\title{
A Preliminary Study of the Design Approaches to Project Work Taken by Undergraduate Engineering Students
}

\author{
J. Laliberté, C. Schramm and A.L. Steele \\ Carleton University \\ jeremy.liberte@carleton.ca, schramm@sce.carleton.ca, asteele@doe.carleton.ca
}

\begin{abstract}
We report on a preliminary study of discrete design processes and their timing, when undergraduate engineering students undertake project work. The method of the study followed the approach undertaken by others ${ }^{I, 2}$ where the project design cycle is broken into discrete stages, for example problem definition, modeling, feasibility analysis and communication. In these previous studies the design was over approximately 3 hours ${ }^{l}$ using a single session design problem and required talking aloud by the designer, so that an observer could assess the stages being undertaken at given time intervals. Our study is over one or two terms and uses self-reporting by students to the criteria. Weekly emails prompted students with individualized links to a webform to report the type of design work done in the previous week. Because a week is a relatively long interval, the web form asks the students to report in terms of their primary (most effort and time) and secondary tasks. Similar to previous studies, this study compares the time spent and the points in the design cycle when certain process are undertaken or revisited. Our results, however, describe the design process over various durations (one term projects or full-year capstone projects), for different years of study (primarily, third and fourth year), different fields of engineering (from Aerospace, Civil, Mechanical, Electrical as well as Systems) and finally for different sized teams (from pairs of students in course projects to teams of twenty in Mechanical and Aerospace capstone projects). Comparisons will also be made between the design processes of different students, based on their final grade for their project. This first year of study is seen as a preliminary year to a longer and broader study, and the paper present our preliminary results as well as lessons learned in the areas of self-reporting and sizeable, longer-term data collection.
\end{abstract}

Keywords: Capstone Project, Engineering Design Process, Teaching Design,

\section{INTRODUCTION}

Design becomes an important part of an engineer's professional work and in their studies a student of engineering may have limited opportunities to experience a 'work-like' design problem in their discipline of study. Indeed there will be different design skills required between disciplines, mechanical engineering students will likely encounter different problems to software engineering students. Individual students will develop these skills at different rates and because of the nature of design it may take longer to develop this ability than say mathematical ability which can have a rapid feedback (the mathematical solution is either correct or incorrect).

Atman and others $[1,2]$ has studied the design stages that either students or practitioners of engineering go through. This was done by using small pen and paper designs with vocal protocols being used and assessed by a trained evaluator. That is usually, the designer is asked to speak aloud as the design is done and that is recorded and then assessed into discrete design activities by an observer of the recording. The general result shows that good designers take an iterative path through the design activities for their designs rather than a single path for weaker designs.

In this work we wanted to examine the design activities students undertake as they progress through their student projects and compare them to these earlier findings based upon short pen and paper designs. The reported work here is preliminary, as the initial processes for recording the various design activities were to be set up and examined for refinement for longer term studies.

The present study has been modeled on previous research into the design process carried out by the Centre for Engineering Learning and Teaching (CELT) [3]. In the prior studies, junior and senior students and established engineers carried out a design project unrelated to their specialization while verbalizing their activities to be recorded. The CELT researchers then transcribed the recordings to generate minute-by-minute breakdowns of each participants' design process. 
Table 1: Engineering Design Activities

\begin{tabular}{|l|l|l|}
\hline Code & Activity & Explanation [4] \\
\hline 8 & $\begin{array}{l}\text { Problem } \\
\text { Definition }\end{array}$ & $\begin{array}{l}\text { Understanding what you are } \\
\text { trying to solve }\end{array}$ \\
\hline 7 & $\begin{array}{l}\text { Information } \\
\text { Gathering }\end{array}$ & $\begin{array}{l}\text { Literature surveys, reading } \\
\text { DRs, manufacturer's data } \\
\text { sheets }\end{array}$ \\
\hline 6 & $\begin{array}{l}\text { Generation of } \\
\text { Ideas }\end{array}$ & $\begin{array}{l}\text { Possible solutions to } \\
\text { problems, or preliminary } \\
\text { designs }\end{array}$ \\
\hline 5 & Modeling & $\begin{array}{l}\text { Establishing how to produce } \\
\text { a solution }\end{array}$ \\
\hline 4 & $\begin{array}{l}\text { Feasibility of } \\
\text { Analysis }\end{array}$ & $\begin{array}{l}\text { Assessment of solutions to } \\
\text { problem }\end{array}$ \\
\hline 3 & Evaluation & $\begin{array}{l}\text { Comparing between possible } \\
\text { solutions when there is more } \\
\text { than one }\end{array}$ \\
\hline 2 & Decision & $\begin{array}{l}\text { Choosing a single approach } \\
\text { to go forward with }\end{array}$ \\
\hline 1 & Communication & $\begin{array}{l}\text { Explaining design stages to } \\
\text { others, such as in DRs or } \\
\text { reviews or presentation to } \\
\text { other groups }\end{array}$ \\
\hline 9 & $\begin{array}{l}\text { No Project } \\
\text { Work Done }\end{array}$ & $\begin{array}{l}\text { Nothing done at all that } \\
\text { week on the project }\end{array}$ \\
\hline
\end{tabular}

\section{Context}

The Faculty of Engineering has four departments: Mechanical and Aerospace Engineering (MAE), Electronics Engineering (EE), Systems \& Computer Engineering (SCE) and Civil and Environmental Engineering (CEE). Each department has different approaches to the capstone engineering project. Selfselected. large scale, multi-year, industry sponsored projects are the norm in the Mechanical and Aerospace Engineering department with teams of 15-25 students supervised by three to five faculty members and additional external experts, For the latter three departments (CSE, EE and CEE), the capstone project teams range between two and four students, which are supervised by one or co-supervised by two faculty members.

Additionally, engineering design is introduced in earlier courses, with design projects. These design courses typically have fewer lecture hours so that the majority of the teaching and contact time is in the laboratory. Students typically are introduced to team work in groups of four to work on a term-length design project.

\section{Problem Definition}

Our objective is to conduct a quantitative survey of the design activities undertaken by students when completing design projects during their course of study. Design is taught at several points in a student's curriculum, within content courses as well as targeted design courses. The capstone project in fourth year typically represents the culmination of experiential learning where students are expected to work on a problem. This Design Process Survey is intended to gather information on a student's approach to solving design problems in their courses or during their capstone design project. This information will be used to improve the teaching of design to future students.

The proposed research project is substantial in scope and demands a sustained and possibly large data collection effort over the course of a year. Data collection, storage and analysis, as well as student participation, were of concern. A pilot study was conducted in the 2012-2013 academic year with the following research goals:

(1) Develop an automatic and accessible method for data collection based on self-reporting.

(2) Evaluate the effect of self-reporting, specifically answering these research questions:

a. What are the validity and reliability of selfreporting?

b. Can the effort of self-reporting be sustained over the course of a year?

(3) Perform a preliminary analysis of the transferability of the academic findings to the classroom.

\section{Solution}

A web service was developed for students to enter their design activities. A reminder email was sent weekly on each Monday, providing a unique URL link to each student by which they would submit a record of their design activities while working during the previous week on a particular course project. The submitted data is stored in a SQL database.

The web form presented to the students via the private URL link presents a set of design activities as named in the CELT design study [3].

\section{Significance of the results}

The design process survey was conducted for the academic year 2012/2013 over the three departments of Mechanical, Electronics and Civil. Out of a total sample size of 259 fourth year project students, a total of 99 
students participated over the course of the academic year, with 23 students providing consistent weekly submissions.

At the time of publication, only the data for the capstone projects has been analysed. The data for projects done in other term courses have been collected but not yet analysed. Also, final grades were not available so no analysis concerning grades could be made. At a macro level, over all students, the data for the trial run reproduces the results of the CELT study. Analysis of the submissions suggests that the effort can be maintained. Data shows some need for improving the web interface to restrict the data and there is a need for improved preparation or training of the students regarding their reporting of their design activities.

The design process survey is documented and posted publicly at [4] as part of the information and openness both required by Research Ethics and sought to achieve buy-in and give thanks to our research participants.

\section{The Design Process Survey}

\subsection{Online Design Process Survey Form}

Each week, students were asked to indicate which two design phases they had spent most of their time on from the week prior. This information formed a weekly "Design Process Journal" that would be scrutinized, as well as returned to the students to look back and see where they spent most of their time.

The contents of the weekly journal is quantitative in nature, following the categorizations of the CELT study[3]. Two values are submitted by the student: the two design activities on which the student spent most of their time during the previous week, called the Primary and the Secondary activity. A dropdown menu in the web form was used to restrict inputs to a set of nine activities, taken as a subset of the design phases identified in [3] and shown in Table 1.

The form was sent to each student through a unique URL formed from the combination of that student's number and the current week.

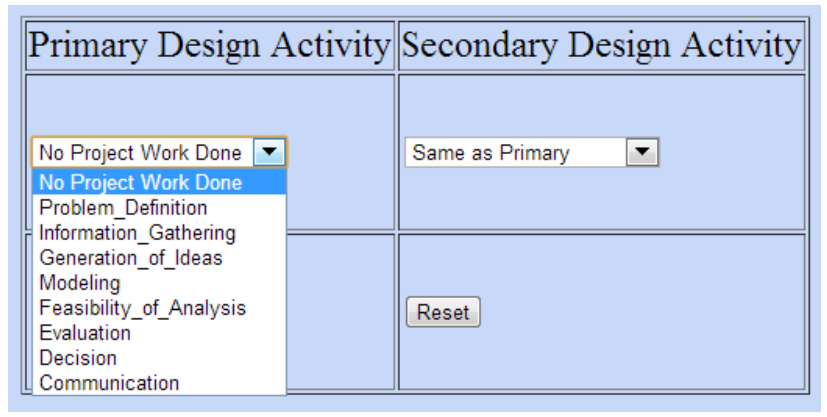

FIG 1. Online Weekly Activity Log

A database held three tables: the list of students (including their department, stream and ultimately their final grade), the list of projects (including the department or course, the number of students, and the faculty supervisor) and the weekly logs with entries crossreferenced to the student's identifier.

\subsection{Preparation or Training}

The survey relies on students correctly reporting their design activities. The web form shown in Figure 1 includes at the bottom the definitions of each activity shown in Table 1. Introductory presentations were also given to the capstone students at the beginning of the year.

\section{RESULTS and DISCUSSION}

At the time of publication, only the data for the capstone projects were analysed.

\subsection{Self-Reporting Participation}

Participation was voluntary and was not monitored, to ensure anonymity until the data is coded. A first concern is the participation rate. Figure 2 illustrates the participation rate as defined by the total number of submissions for each week, from September to April. Terms are nominally thirteen weeks long. Weeks 14 and 15 correspond to the exam period and Christmas break in December. Week 18 is the winter study break. With two exceptions, the participation rate is above 30, a minimal but acceptable sample size for this initial study. 


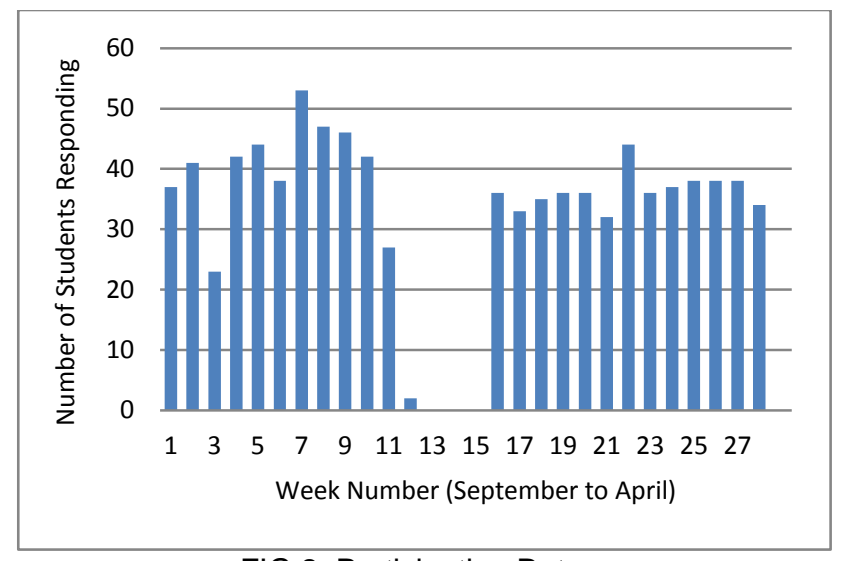

FIG 2: Participation Rates

A second concern was in maintaining consistent participation. Ideally, the data would contain a complete journal of activities for a single student over the entire course of the year. Figure 3 depicts the sustained rate of participation with each bar showing the number of students who submitted a given number of activity reports. With a skewed mode $=1$ with 18 students submitting only once over the whole year, it is evident that best intentions easily fail, and that the drop-out rate is very high. The second mode on the right (18-23) does provide promise that students can maintain the effort over the course of the year.

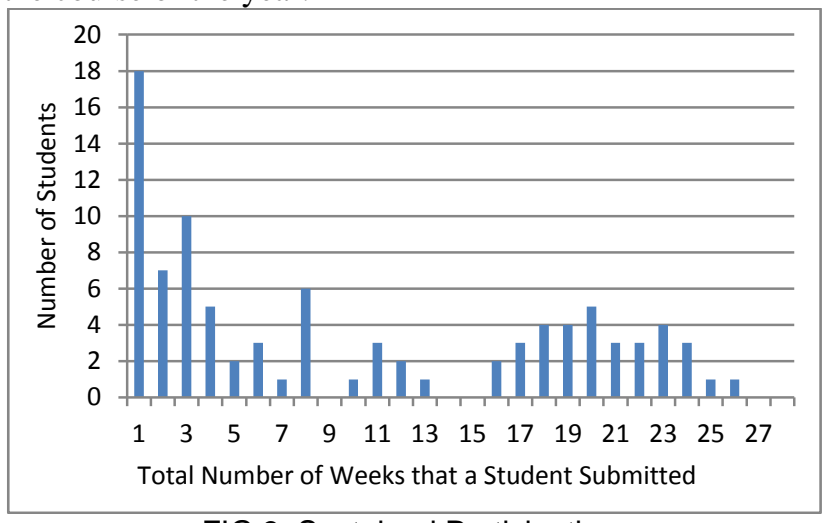

FIG 3: Sustained Participation

\subsection{Validity and Reliability}

In the CELT study, observers were trained on how to interpret and map a student's activities onto the nine design activities. The training would ensure both validity and inter-rater reliability.

An indicator of the inter-rater reliability of our selfreporting survey is provided by the option "No Project Work Done". The data showed that this option was selected as the Primary Activity by 53 students, and as the Secondary Activity by 147 students, over all weeks. The two numbers should be equal. If there was a Primary
Activity (no matter how small in time or effort) and there was no time for anything else, the Secondary Activity should be the same as the Primary Activity. The data suggests that students mistook the words "Primary" and "Secondary" to also connote some level of effort or time because, in weeks of low activity, they chose a Primary Activity (to say they did some work) and then selected "No Project Work Done" for the Secondary Activity (to say that they didn't have time for anything else).

Within the current research method, there is no measure to indicate validity. We do not know whether students correctly identified their activities.

\subsection{Preliminary Survey Results}

At the macro level - without any breakdown per student, project size, or department - the survey did yield a picture of the engineering design activities over the course of capstone project. The results are presented in two graphs in Figure 4, for the fall and winter term, using the numbering for the design activities in Table 1 to improve the visibility of the charts.

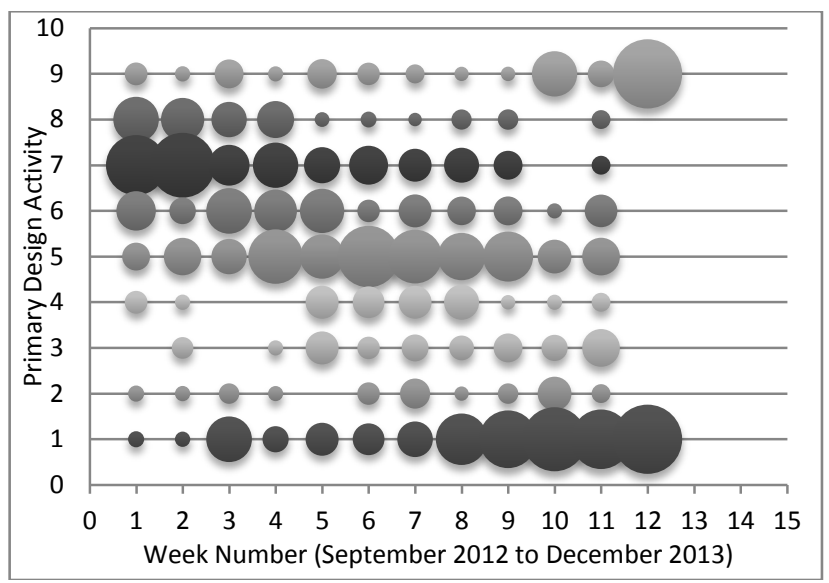

a) Fall Term

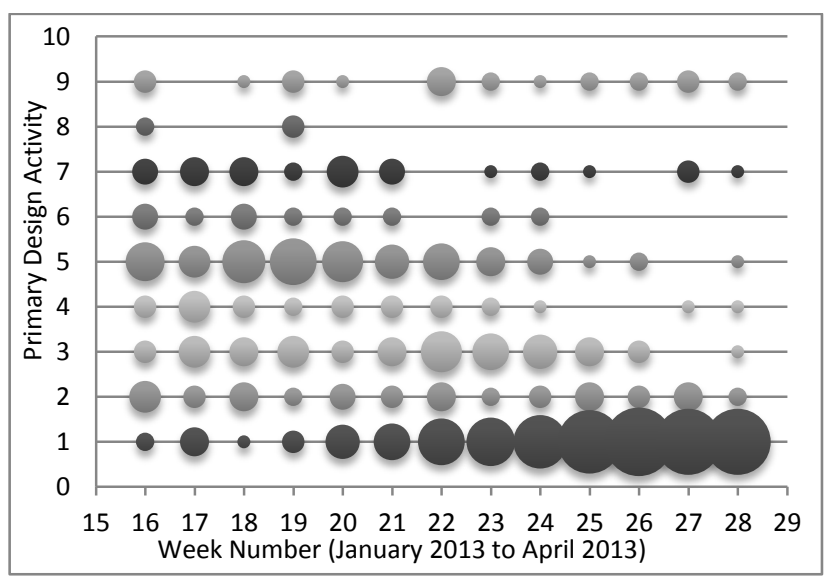

b) Winter Term

FIG 4: Primary Weekly Design Activity 


\section{CONCLUSION and FUTURE WORK}

The trial run was successful. The timing and concentration of design activities were tracked over the course of a year for a large sample of students. We can expect to gain some interesting insights from the Design Process Survey to be run in full in the academic year 2013-2014, once the weaknesses of our methodology have been addressed.

Added constraints need to be added to the web service. The web form shall further enforce relationships between the Primary and Secondary Activities. The list of activities may also be expanded to include others defined in the CELT student[3], particularly Implementation. The URLs sent to the students in the email will also be set to expire. Reminder emails will be sent mid-way through the week only to those students who have not yet submitted, in an effort to maintain participation.

Training of the students - possibly including their supervisors - needs to be improved to address concerns of reliability and validity. An introductory workshop is planned for each major group of students in which the meaning of each design activity will be explained and related to the different fields of engineering. The concise explanations included in the web form will be augmented by links to field-related exemplars.

\section{Acknowledgements}

We would like to thank all the fourth year engineering undergraduate students who participated in our study.

\section{References}

[1] Cynthia J Atman, Deborah Kilgore and Ann McKenna. "Characterizing Design Learning: A Mixed-Methods Study of Engineering Designers' Use of Language", in Journal of Engineering Education, pp309-326, July 2008.

[2] Cynthia J Atman, RS Adams, ME Cardella, J Turns, S Mosborg and J. Saleem, "Engineering Design Processes: A comparison of student and expert practitioners" , Journal of Engineering Education, pp359-379, Oct 2007.

[3] Cynthia J Atman, J Brogford-Parnell and J Turns, Studying Student and Expert Engineering and Design Processes, CELT ENGINEERING AND DESIGN NOTE, Available as of 2007 from http://depts.washington.edu/celtweb/research/Research\%20\&\%2 0Applications\%20Handout.pdf.

CEEA13; Paper 83

Montreal, QC; June 17-20, 2013
[4] Design Process Survey. [online] Available as of September 2012 